\title{
Whole-exome sequencing reveals the etiology of the rare primary hepatic mucoepidermoid carcinoma
}

Ping Hou ${ }^{1 \dagger}$, Xiaoyan $\mathrm{Su}^{2 \dagger}$, Wei $\mathrm{CaO}^{3}$, Liping Xu${ }^{4}$, Rongguiyi Zhang ${ }^{1}$, Zhihao Huang ${ }^{1}$, Jiakun Wang ${ }^{1}$, Lixiang Li ${ }^{2}$, Linquan $\mathrm{Wu}^{1 *}$ and Wenjun Liao ${ }^{1 *}$

\begin{abstract}
Background: Primary hepatic mucoepidermoid carcinoma (HMEC) is extremely rare and the molecular etiology is still unknown. The CRTC1-MAML2 fusion gene was previously detected in a primary HMEC, which is often associated with MEC of salivary gland in the literature.
\end{abstract}

Methods: A 64-year-old male was diagnosed with HMEC based on malignant squamous cells and mucus-secreting cells in immunohistochemical examination. Fluorescence in situ hybridization (FISH) was used to detect the CRTC1MAML2 fusion gene in HMEC. Whole-exome sequencing and Sanger sequencing were used to reveal the molecular characteristics of HMEC and analysis was performed with public data. Pedigree investigation was performed to identify susceptibility genes.

Results: Hematoxylin-eosin staining and immunohistochemistry revealed that the tumor cells were composed of malignant epidermoid malignant cells and mucous cells, indicating a diagnosis of HMEC. The CRTC1-MAML2 fusion gene was not detected in the primary HMEC, and somatic mutations in GNAS, KMT2C and ELF3 genes were identified by sequencing. Analyses of public data revealed somatic GNAS alterations in $2.1 \%$ hepatobiliary tumors and relation with parasite infection. Heterozygous germline mutations of FANCA, FANCI, FANCJ/BRIP1 and FAN1 genes were also identified. Pedigree investigation verified that mutation of Fanconi's anemia susceptibility genes were present in the pedigree.

Conclusions: Here we provide the first evidence of the molecular etiology of a rare HMEC associated with germline Fanconi's anemia gene mutations and somatic GNAS R201H mutation.

Keywords: Hepatic mucoepidermoid carcinoma (HMEC), Somatic GNAS R201 mutation, Germline Fanconi's anemia mutation, Whole exome-sequencing (WES)

\footnotetext{
* Correspondence: Wulqnc@163.com; liaowenjun120@163.com

†Ping Hou and Xiaoyan Su contributed equally to this work.

'Department of Hepatobiliary and Pancreatic Surgery, The Second Affiliated

Hospital of Nanchang University, No.1, Minde Road, Nanchang, China

Full list of author information is available at the end of the article
}

\section{$\triangle B M C$}

(c) The Author(s). 2021 Open Access This article is licensed under a Creative Commons Attribution 4.0 International License, which permits use, sharing, adaptation, distribution and reproduction in any medium or format, as long as you give appropriate credit to the original author(s) and the source, provide a link to the Creative Commons licence, and indicate if changes were made. The images or other third party material in this article are included in the article's Creative Commons licence, unless indicated otherwise in a credit line to the material. If material is not included in the article's Creative Commons licence and your intended use is not permitted by statutory regulation or exceeds the permitted use, you will need to obtain permission directly from the copyright holder. To view a copy of this licence, visit http://creativecommons.org/licenses/by/4.0/. The Creative Commons Public Domain Dedication waiver (http://creativecommons.org/publicdomain/zero/1.0/) applies to the data made available in this article, unless otherwise stated in a credit line to the data. 


\section{Background}

Mucoepidermoid carcinoma (MEC) is a relatively common malignant neoplasm of the salivary gland that is mainly characterized by the pathological manifestation of mucous cells, intermediate cells and epidermoid malignant cells in intimately mixed nests. MEC also occurs at low frequencies at other sites, such as the esophagus, thyroid gland, lacrimal gland, lung, thymus, breast, anal canal, uterine cervix, hepatobiliary system and the pancreatic system [1]. Over $50-60 \%$ of salivary MEC (SMEC) cases are associated with a fusion gene, CRTC1/CRTC3$M A M L 2$, which results from the chromosomal translocation $\mathrm{t}(11 ; 19)(\mathrm{q} 21 ; \mathrm{p} 13)$ [2]. The CRTC1-MAML2 fusion gene was also observed in primary cervical MEC [3] and bronchopulmonary MEC [4], which are different from adenosquamous carcinoma. However, pancreatic MEC did not show the CRTC1/3-MAML2 fusion and was a morphologic variant of pancreatic adenosquamous carcinoma [5]. The presence of the CRTC1-MAML2 fusion gene in primary hepatic MEC (HMEC) was controversial $[6,7]$.
MEC was also associated with hematopoietic stem cell transplant in Fanconi's anemia patients [8]. So far, only 23 cases with primary hepatobiliary MEC (including hepatic, biliary and gallbladder MEC) that were pathomorphologically similar to SMEC have been reported in the literature (Table 1), but the molecular etiology of HMEC is still unknown. Here we revealed the genetic abnormality of a primary HMEC by whole-exome sequencing (WES).

\section{Methods}

\section{Case material}

A 64-year-old male was admitted to the Second Affiliated Hospital of Nanchang University on September 16, 2019 with a complaint of repeated abdominal distension over a period of 1 year. He had a previous history of icteric hepatitis and unknown biliary tract surgery 30 years prior and coronary artery stenosis disease with an implanted stent 1 year ago. No abnormality was found in the physical examination. Most preoperative laboratory tests were in the normal range, including serum

Table 1 Basic characteristics of 23 patients with primary hepatobiliary mucoepidermoid carcinoma, including in the liver, gallbladder and biliary tract, reported in the literature

\begin{tabular}{|c|c|c|c|c|c|c|c|c|c|c|c|c|c|c|}
\hline Case & Year & Area & $\begin{array}{l}\text { Age } \\
\text { (year) }\end{array}$ & Gender & Location & Metastasis & $\begin{array}{l}\text { Size } \\
(\mathrm{cm})\end{array}$ & Hepatitis & $\begin{array}{l}\text { AFP } \\
\mathrm{ng} / \mathrm{ml}\end{array}$ & $\begin{array}{l}\text { CA199 } \\
\mathrm{u} / \mathrm{ml}\end{array}$ & $\begin{array}{l}\text { CEA } \\
\mathrm{ng} / \mathrm{ml}\end{array}$ & Treatment & $\begin{array}{l}\text { OS } \\
\text { (day) }\end{array}$ & Reference \\
\hline 1 & 1971 & Argentina & 44 & $M$ & $\mathrm{RL}$ & Non & 15 & $\mathrm{~Np}$ & $\mathrm{~Np}$ & $\mathrm{~Np}$ & $\mathrm{~Np}$ & $\mathrm{~S}$ & 45 & \\
\hline 2 & 1980 & Hong Kong & 65 & $M$ & $\mathrm{RL}$ & Y & 8 & $\mathrm{~Np}$ & $\mathrm{~Np}$ & $\mathrm{~Np}$ & $\mathrm{~Np}$ & Con & 14 & \\
\hline 3 & & Hong Kong & 63 & F & $\mathrm{LL}$ & Y & 6 & $\mathrm{~Np}$ & $\mathrm{~Np}$ & $\mathrm{~Np}$ & $\mathrm{~Np}$ & Con & 16 & \\
\hline 4 & 1982 & Hong Kong & 44 & $\mathrm{~F}$ & $\mathrm{LL}$ & Non & 12 & HBV & $\mathrm{Np}$ & $\mathrm{Np}$ & $\mathrm{Np}$ & $S+C$ & 180 & 49 \\
\hline 5 & & Hong Kong & 66 & $M$ & $\mathrm{BD}$ & Y & 4 & Non & $\mathrm{Np}$ & $\mathrm{Np}$ & $\mathrm{Np}$ & PTCD+S & 7 & \\
\hline 6 & & Hong Kong & 62 & $M$ & $\mathrm{BD}$ & Non & 1.5 & Non & $\mathrm{Np}$ & $\mathrm{Np}$ & $\mathrm{Np}$ & S & $300+$ & \\
\hline 7 & 1984 & Japan & 78 & $M$ & $\mathrm{LL}$ & Y & 11 & $\mathrm{~Np}$ & 12.5 & $\mathrm{~Np}$ & 1300 & C & 90 & 42 \\
\hline 8 & 1986 & Krean & 35 & $M$ & $\mathrm{LL}$ & Non & 18 & $\mathrm{~Np}$ & $<5$ & $\mathrm{~Np}$ & $\mathrm{~Np}$ & Con & 14 & \\
\hline 9 & 1986 & Australia & 59 & $\mathrm{~F}$ & $\mathrm{RL}$ & Y & 18 & $\mathrm{~Np}$ & $\mathrm{~Np}$ & $\mathrm{~Np}$ & $\mathrm{~Np}$ & $S$ & 14 & \\
\hline 10 & 1987 & Japan & 46 & $F$ & $\mathrm{LL}$ & Non & 3 & $\mathrm{~Np}$ & 20 & $\mathrm{~Np}$ & $\mathrm{~Np}$ & S & 330 & 30 \\
\hline 11 & 1992 & Italy & 66 & F & $\mathrm{LL}$ & Y & 9.5 & Non & $<5$ & 500 & $<2$ & S & 180 & 41 \\
\hline 12 & 1994 & Krean & 68 & $M$ & $\mathrm{LL}$ & Non & 10 & $\mathrm{~Np}$ & $\mathrm{~Np}$ & $\mathrm{~Np}$ & $\mathrm{~Np}$ & $\mathrm{TACE}+\mathrm{C}$ & 1095 & \\
\hline 13 & 2000 & Thailand & 64 & $M$ & $\mathrm{LL}$ & Y & 5 & $\mathrm{~Np}$ & $\mathrm{~Np}$ & $\mathrm{~Np}$ & $\mathrm{~Np}$ & Con & 210 & \\
\hline 14 & 2003 & Krean & 52 & $M$ & $\mathrm{LL}$ & Y & 7 & $\mathrm{~Np}$ & $<5$ & 400 & $\mathrm{~Np}$ & S & 180 & 28 \\
\hline 15 & 2004 & Krean & 69 & $\mathrm{~F}$ & $\mathrm{RL}$ & Y & 16 & Non & $<5$ & 240 & $\mathrm{~Np}$ & $S$ & 120 & \\
\hline 16 & 2008 & Japan & 81 & F & $\mathrm{RL}$ & Y & 10 & Non & $<5$ & 14,893 & $\mathrm{~Np}$ & C & 117 & \\
\hline 17 & 2011 & Krean & 70 & $M$ & $\mathrm{BD}$ & Y & 8 & $\mathrm{HCV}$ & $<5$ & 349 & $\mathrm{~Np}$ & $R+C$ & 106 & \\
\hline 18 & 2012 & Japan & 68 & $M$ & $\mathrm{BD}$ & Y & 5 & Non & $\mathrm{Np}$ & 50.8 & $\mathrm{~Np}$ & $S+R+C$ & $90+$ & 29 \\
\hline 19 & 2013 & America & 83 & $\mathrm{~F}$ & $\mathrm{BD}$ & Y & 2 & $\mathrm{~Np}$ & $\mathrm{~Np}$ & 940 & 10 & $S+C$ & 390 & 7 \\
\hline 20 & 2014 & China (mainland) & 60 & F & $\mathrm{LL}$ & Y & 8.5 & Non & $<5$ & 50 & $\mathrm{~Np}$ & $S+R$ & 180 & \\
\hline 21 & 2019 & India & 50 & $M$ & GB & Y & 8 & Non & $<5$ & 652 & 77 & S & 180 & 1 \\
\hline 22 & 2019 & Japan & 79 & $\mathrm{~F}$ & $\mathrm{RL}$ & Y & 4 & Non & $<5$ & 415 & 146 & $S+R+C$ & $3650+$ & 6 \\
\hline 23 & 2020 & China (mainland) & 60 & $M$ & $\mathrm{LL}$ & Non & 13 & Non & $<5$ & 151 & 10 & S & 90 & present \\
\hline
\end{tabular}

Abbreviations: Non Not have, Np Not provided, RL Right liver, LL Left liver, BD Bile duct, GB Gallbladder, HCC Hepatocellular carcinoma, CC Cholangiocarcinoma, ASC Adenosquamous carcinoma, GBC Gallbladder carcinoma, S Surgery, R: Radiotherapy, C Chemotherapy, Con Conservative, TACE Transcatheter arterial chemoembolization, PTCD Percutaneous transhepatic cholangial drainage, OS Overall survival 
glutamic pyruvic transaminase, glutamic oxaloacetic transaminase, total bilirubin, electrolyte, glucose and platelet count and serum alpha fetoprotein level. Hepatitis $\mathrm{B}$ surface antigen and hepatitis $\mathrm{C}$ antibody were both negative. Abnormal blood test results included $\mathrm{C}$ reactive protein $112.3 \mathrm{mg} / \mathrm{l}$ (normal value, $<10 \mathrm{~g} / \mathrm{l}$ ), white blood cell $9.82 \times 10^{9} / 1$ (normal value, $3.5 \times 10^{9} / 1$ ), red blood cell $3.68 \times 10^{9}$ (normal value, $4.3-5.8 \times 10^{9} / \mathrm{l}$ ), hemoglobin $103 \mathrm{~g} / \mathrm{l}$ (normal value 130-175 g/l), alkaline phosphatase 483.9 U/L (normal value 45-125 U/L), $\gamma$ glutamine dehydrogenase $404.84 \mathrm{U} / \mathrm{L}$ (normal value 10$60 \mathrm{U} / \mathrm{L}$ ), carcinoembryonic antigen (CEA) $10.2 \mathrm{ng} / \mathrm{mL}$ (normal value, $<5.0 \mathrm{ng} / \mathrm{mL}$ ) and carbohydrate antigen 19-9 (CA19-9) 151.2 U/mL (normal value, <37 U/mL). The abdominal non-contrast computer tomography (CT) scan revealed a low density mass measuring approximately $10 \mathrm{~cm}$ in diameter at the left hepatic lobe and intrahepatic bile ducts with multiple stones (white arrow) (Fig. 1a). Enhanced CT scan (arterial phase) revealed a heterogeneous enhanced mass in the left lobe of the liver (Fig. 1b); enhanced CT scan (portal phase) revealed a persistent inhomogeneous enhanced mass and formation of tumor thrombus in the left branch of the portal vein (Fig. 1c) and a persistent inhomogeneous enhanced mass in delayed phase (Fig. 1d). Ultrasonography and magnetic resonance imaging further validated the results of CT. Gastroscopy revealed chronic nonatrophic gastritis. Bone scan and chest $\mathrm{CT}$ were performed and excluded metastatic disease. CT scan revealed no solid mass in the head and neck, parotid gland, thyroid gland and pituitary gland (data not shown). The patient underwent resection with left hemihepatectomy and choledocholithotomy and T-tube drainage. The patient was diagnosed with HMEC based on malignant squamous cells and mucus-secreting cells in pathological examination. There was gradually increased jaundice in the postoperative term, and the patient died of hepatic function failure at postoperative 3 months.

This study was approved by the Ethics Committee of the Second Affiliated Hospital of Nanchang University, and informed consent was obtained from the patient and his family. Parts of tumor tissues and corresponding non-tumor tissues were immediately conserved in a liquid nitrogen tank at $-80^{\circ} \mathrm{C}$. Some tissue samples were fixed in $10 \%$ formaldehyde and paraffin-embedded for pathological diagnosis and immunohistochemistry. Exome sequencing and Sanger sequencing were performed in fresh tumor tissue and corresponding non-tumor tissue. The WES data from this study were deposited in NCBI Sequence Read Archive under accession SRA:SRP 266690.

\section{Histopathological examination}

Hematoxylin-eosin staining and immunohistochemistry were performed on tumor samples and corresponding non-tumor samples following standard procedures. Primary antibodies included antibodies against MUC1 (1: 200), MUC5AC (1:200), CK7 (1:250), CK19 (1:150), p63 (1:150) and CEA (1:250) (all from Leica, Wetzlar, Germany). All tissue sections were processed using the Lab Vision system (Thermo Scientific, Kalamazoo, MI, USA). The two senior pathology specialists from the Affiliated Hospital of NanChang University (XY Su and LP
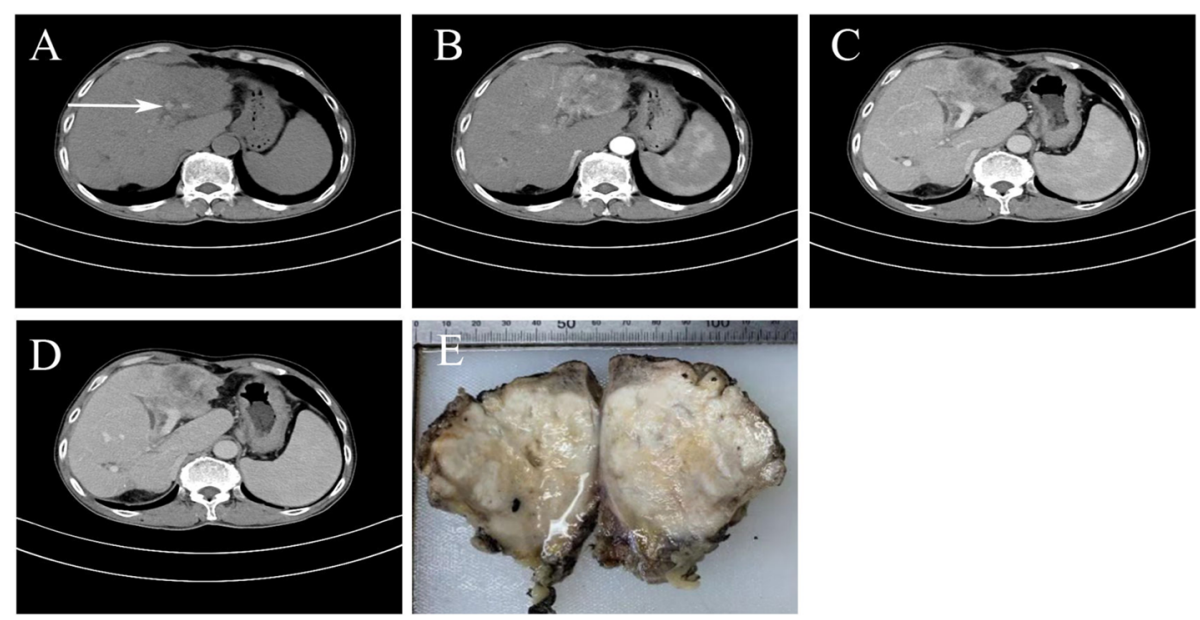

Fig. 1 Results of preoperative CT, postoperative gross examination. a Abdominal non-contrast CT scan revealed a low density mass measuring approximate $10 \mathrm{~cm}$ in diameter at the left hepatic lobe and intrahepatic bile ducts with multiple stones (white arrow). $\mathbf{b}$ Enhanced CT scan (arterial phase) revealed a heterogeneous enhanced mass in the left lobe of the liver. c Enhanced CT scan (portal phase) revealed a persistent inhomogeneous enhanced mass and formation of tumor thrombus in the left branch of portal vein. $\mathbf{d}$ Enhanced $\mathrm{CT}$ scan (delayed phase) revealed a persistent inhomogeneous enhanced mass. e Gross examination of the resected liver mass indicated an irregular, white solid tumor without a fibrous capsule. The border between the tumor and normal liver tissue was indistinct 
$\mathrm{Xu}$ ) who examined the results suggested a diagnosis of HMEC.

\section{Fluorescence in situ hybridization (FISH) analysis}

FISH was performed on formalin-fixed paraffinembedded sections of HMEC using a commercially available Dual Color fusion Probe (F.01358, Anbiping Medical Laboratory, Guangzhou, China) following the manufacturer's instructions. Green fluorescence-labeled CRTC1/MECT1 (19p13) probe (G) and red fluorescence-labeled MAML2 (11q21) probe (R) were used to evaluate the fusion gene. In samples harboring the fusion gene, the green signal and the red signal from probe binding generates a yellow signal (F). The normal signal mode is $2 \mathrm{G} 2 \mathrm{R}$ and the typical positive signal mode is 1G1R2F. Histopathology was evaluated by pathologists to determine the tumor and hybridization area. FISH was performed for the CRTC1/MECT1-MAML2 fusion gene and 200 interphase tumor cells were examined in at least two visual fields.

\section{WES}

Exome capture was performed using $0.6 \mu \mathrm{g}$ genomic DNA per sample. Sequencing libraries were generated using the Agilent SureSelect Human All Exon V6 kit (Agilent Technologies, CA, USA). The DNA libraries were sequenced on an Illumina HiSeq platform and 150 bp paired-end reads were generated. The original fluorescence image files were transformed to raw data by base calling and clean data were recorded in FASTQ format. Valid sequencing data were mapped to the reference human genome (UCSC hg19) by Burrows-Wheeler Aligner software [9] and results were stored in BAM format. Samtools mpileup and bcftools were used for variant calling and to identify single-nucleotide variants (SNVs) and InDel [10]. Functional annotation ANNOVAR was performed for annotation for Variant Call Format and detecting variants by 1000 Genome, dbSNP and other databases [11-13]. Given the significance of exonic variants, gene transcript annotation databases such as Consensus CDS, RefSeq, Ensembl and UCSC were also included to determine amino acid alterations [14]. Using the paired samples of tumor tissue and corresponding non-tumor tissues, somatic SNVs were detected by MuTect [15], somatic InDels by Strelka [16] and somatic CNVs by Control-FREEC [17]. SIFT, Polyphen/Polyphen2 and MutationAssessor were used to predict the impact of SNVs on function [18-20]; and truncated mutations (nonsense and frameshift) also resulted in high functional impact alterations.

\section{Public data analysis}

The search and analytic strategy was performed using public data (http://www.cbioportal.org/) [21, 22]. SNVs were examined in hepatocellular carcinoma (HCC) and cholangiocarcinoma (CHL). We also downloaded SMEC SNV data [23] from published studies to examine the relation between the alterations in the current case with downloaded data. We used an online tool to construct Venn diagrams (https://bioinfogp.cnb.csic.es/tools/ venny/).

\section{Sanger sequencing and pedigree survey}

Purified DNA was isolated from fresh tumor tissue and corresponding non-tumor tissue from the proband and peripheral blood lymphocytes of four family members using the TIANamp Genomic DNA Kit (Beijing Biotech, China). PCR was performed using the PTC-200PC instrument (BIO-RAD, USA). Primer sequences are shown in Supplementary Table 1. The PCR products were examined using an ABI 3730XL DNA Analyzer (Applied Biosystems, USA).

\section{Results}

Microscopic features and immunohistochemistry

The mass was an irregular specimen measuring approximately $10 \times 7 \times 6 \mathrm{~cm}$, revealing no fibrous capsule and tough solid texture; resection from the middle edge showed grayish-white nodules without necrosis. Black pigment stones were also found in the small intrahepatic bile duct (Fig. 1e). The resection edges were free of tumor. There was an absence of cirrhosis in the corresponding non-tumor sample, but massive inflammatory cell infiltration was observed in tumorous and portal areas (Fig. 2a). Hematoxylin and eosin staining revealed that the tumor cells were composed of epidermoid malignant cells, mucous cells and intermediate cells (Fig. 2b). The distribution of epidermoid cells was not nest-like but was surrounded with intercellular bridges, with only a few glandular structures and occasional keratinization. Mucinproducing cells showed mainly abundant clear cytoplasm with eccentric pyknotic nuclei and predominantly showed intracellular mucus and rare extracytoplasmic mucin (Fig. 2c). The heterogeneity of epidermoid cells was obvious, with infiltrated stroma and invasion, but nerve, lymphovascular, blood invasion and necrosis were not apparent. Alcian blue staining revealed mucin in mucin-producing cells (Fig. 2d).

Immunohistochemically, MUC5AC was only positive in the cytoplasm of malignant mucous cells (Fig. 3a). Positive MUC1 was detected at the squamous and mucous tumor cell membrane (Fig. 3b). p63 was diffusely positive in the nuclei of malignant squamoid cells (Fig. 3c). Cytoplasmic CK19 was diffusely positive in malignant squamoid cells and mucous cells (Fig. 3d), and cytoplasmic CK7 was diffuse positive in malignant mucous cells (Fig. 3e). CEA was only focal positive in malignant mucous cells (Fig. 3f). 


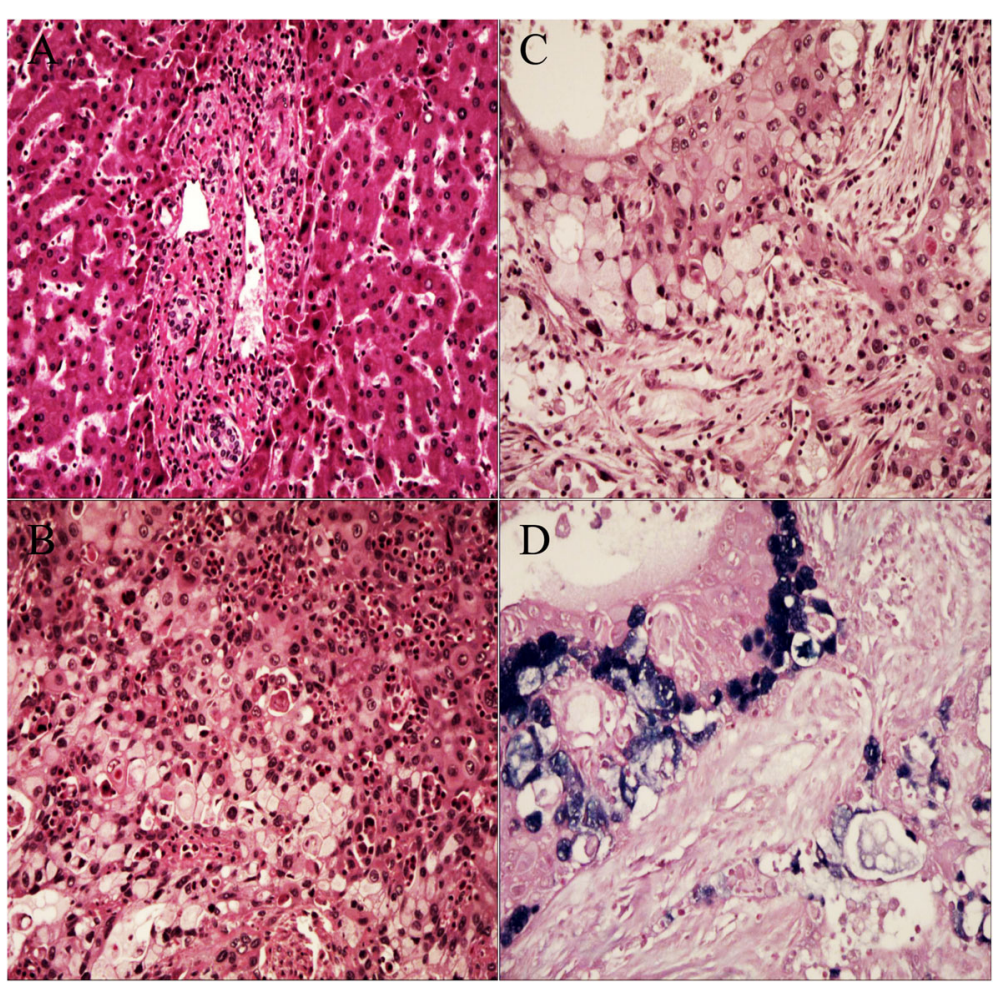

Fig. 2 Pathological results. a Dystrophic arteries and a large number of inflammatory cells, mainly including lymphocyte infiltrations, were observed in the portal area (hematoxylin and eosin (H\&E) staining, magnification 100X). b Eosinophil infiltrations were seen in the tumor area (H\&E staining, magnification 200x). c H\&E staining revealed malignant epidermoid cells and mucus-producing cells with intracytoplasmic mucin. The tumor cells infiltrated into the stroma with occasional keratinization (magnification 200x). $\mathbf{d}$ Alcian blue stain-positive material highlights the mucin in mucin-producing cells (magnification 200x)

\section{FISH}

FISH analysis for the CRTC1/MECT1-MAML2 fusion gene revealed negative results. Two hundred interphase cells were analyzed. The signal patterns were as follows: 2G2R, 7.5\%; 3G2R, 40.0\%; 3G1R, 5.0\%; 4G3R, 10.0\%; 4G2R, 5.0\%; 4G4R, 7.5\%; 2G3R, 5.0\%; 3G4R, 5.0\%; 2G1R, 5.0\%; 3G3R, 7.5\%; and 5G3R, 2.5\% (Fig. 4).

\section{Somatic variants in the proband}

The sequencing of tumor tissue and corresponding nontumor tissue in proband provided an average depth on target of $175 \mathrm{X}$ and $112 \mathrm{X}$, respectively, and the $>10 \mathrm{X}$ coverage of the targeted gene regions in tumor tissue and corresponding non-tumor tissue were 94 and 98\%, respectively. The total somatic variants included 135 SNVs (53 missenses, 31 synonymous, 3 nonsense and others) and 4 InDels (2 frameshift insertions and 2 frameshift deletions). A total of $252 \mathrm{CNVs}$ (126 gain, 126 loss) were identified in 2591 genes (629 gene gain, 1691 gene loss). GNAS mutation (NM_000516:exon8: c.G602A:p.R201H) was detected in both the tumor tissue and corresponding non-tumor tissue by WES, but the wild-type gene was determined in the corresponding non-tumor tissue by Sanger sequencing. In addition, protein-truncating genetic variants included a frameshift indel mutation in ELF3 (c.909dupC:p.F303fs), and nonsense mutations in DOCK3 (c.C2483A:p.S828X) and KMT2C (c.C1519T:p.Q507X) were detected in tumor samples by Sanger sequencing (Fig. 5D). A Circos map visually summarizes the somatic genomic variations of SNVs, INDEL and CNVs of the HMEC in Supplementary Figure 1.

\section{Bioinformatics analysis}

A total of 1004 significant mutated genes (source: Onco $\mathrm{KB}$ ) in SNVs from 8 studies containing $1487 \mathrm{HCC}$ patients (Supplementary Fig. 2A) and 654 significant mutated genes (source: Onco KB) in SNVs from 7 studies containing $445 \mathrm{CHL}$ patients were downloaded (Supplementary Fig. 2B) (www.cbioportal.org). We also obtained 312 significant mutated genes in SNVs from 18 SMEC patients from the study by Kang et al. Six SNVs (in STAT1, TGFBR1, NOTCH1, KMT2C, ELF3 and GNAS) in the HMEC overlapped with those in primary liver tumors (HCC and CHL), and only an SNV in the CHD3 gene in HMEC overlapped with SMEC (Fig. 5A). Somatic GNAS gene alterations (including missense mutation, amplification and truncating mutation) were 


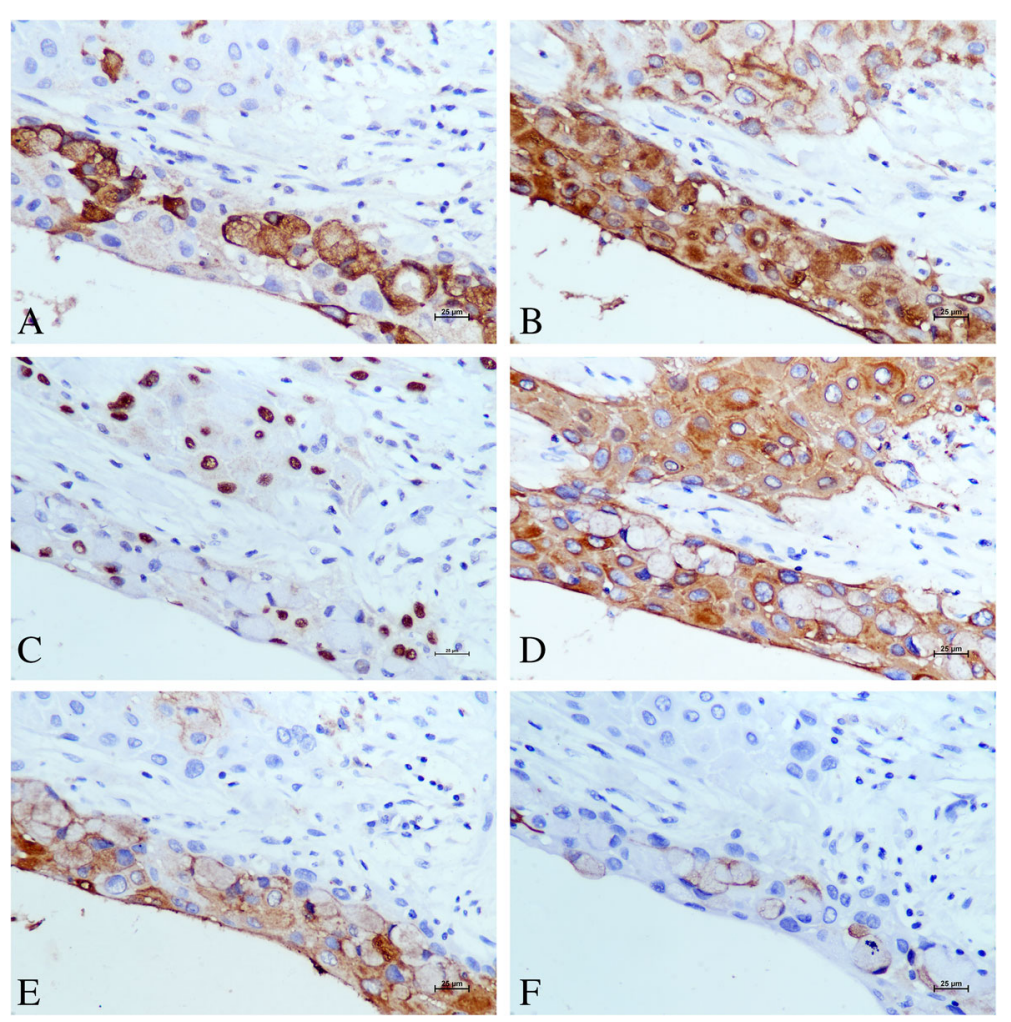

Fig. 3 Immunohistochemical results. a Immunopositivity for cytoplasmic MUC5AC was detected in malignant mucinous cells, with negative staining in malignant epidermoid cells (magnification 400X). b Immunopositivity for membrane MUC1 was detected in all malignant epidermoid cells and mucinous cells (magnification 400x). c Immunopositivity for p63 was only detected in the nuclei of malignant epidermoid cells (magnification 400x). d Cytoplasmic CK19 staining was diffusely positive in the malignant epidermoid and mucous component of the tumor (magnification 400X). e Cytoplasmic CK7 staining was focally positive in the malignant epidermoid and mucous component of the tumor (magnification 400x). $\mathbf{f}$ Mucous component of the tumor was focally positive for membrane CEA staining (magnification 400x)

detected in $2.1 \%(9 / 445)$ patients with primary hepatobiliary tumors including intrahepatic cholangiocarcinoma, extrahepatic cholangiocarcinoma and perihilar cholangiocarcinoma (Fig. 5B). Three patients showed GNAS (p.R201H/C) missense mutation (a putative driver) in exon 8. In addition, Sample ID (W012,T026) were Opisthorchis viverrini-associated cholangiocarcinoma (SRP007970) (Fig. 5C).

\section{Germline variants in the proband and pedigree analysis}

The 56 germline variants in 20 Fanconi's anemia pathway genes included 19 missense variants, 25 synonymous variants and 12 UTR3 and UTR5 in the proband corresponding non-tumor tissue detected by WES (Supplementary Table 2). Five germline homozygous variants and six germline heterozygous variants in six Fanconi's anemia pathway genes (FANCA, FANCI, FANCW/ RFWD3, FANCD1/BRCA2, FANCJ/BRIP1, FAN1) were identified in the proband's non-tumor tissue by Sanger sequencing (Table 2, Fig. 6A).

There was no family history of Fanconi's anemia and solid tumor. The proband's parents died of cardiovascular and cerebrovascular diseases 10 years ago. The older sibling showed hypertension and type 2 diabetes, and the proband's offspring did not show any disease. The same mutational variants in FANCD1/BRCA2, FANCW/RFWD3 and FAP100/C17orf70 were verified in the pedigree. Heterozygous variants in FANCA (c.G1501A:p.G501S), FANCA (c.A796G:p.T266A) and FANCJ/BRIP1 (c.T2755C:p.S919P) were detected in the proband, but homozygous mutations were shown in the other family members. Heterozygous FAN1 variants were detected in the siblings and proband. Only heterozygous FANCI variants (c.C257T:p.A86V and c.G2225C:p.C742S) were unique in the proband (Table 2, Fig. 6B, C).

\section{Discussion}

The correlation between two rare diseases is really difficulty for clinicians. The emergence of next-generation sequencing technologies has provided a simple and powerful approach for discovering de novo diseaseassociated genes, and these methods have furthered our understanding of the rare HMEC, which is not associated with traditional high risk factors such as hepatitis B, 

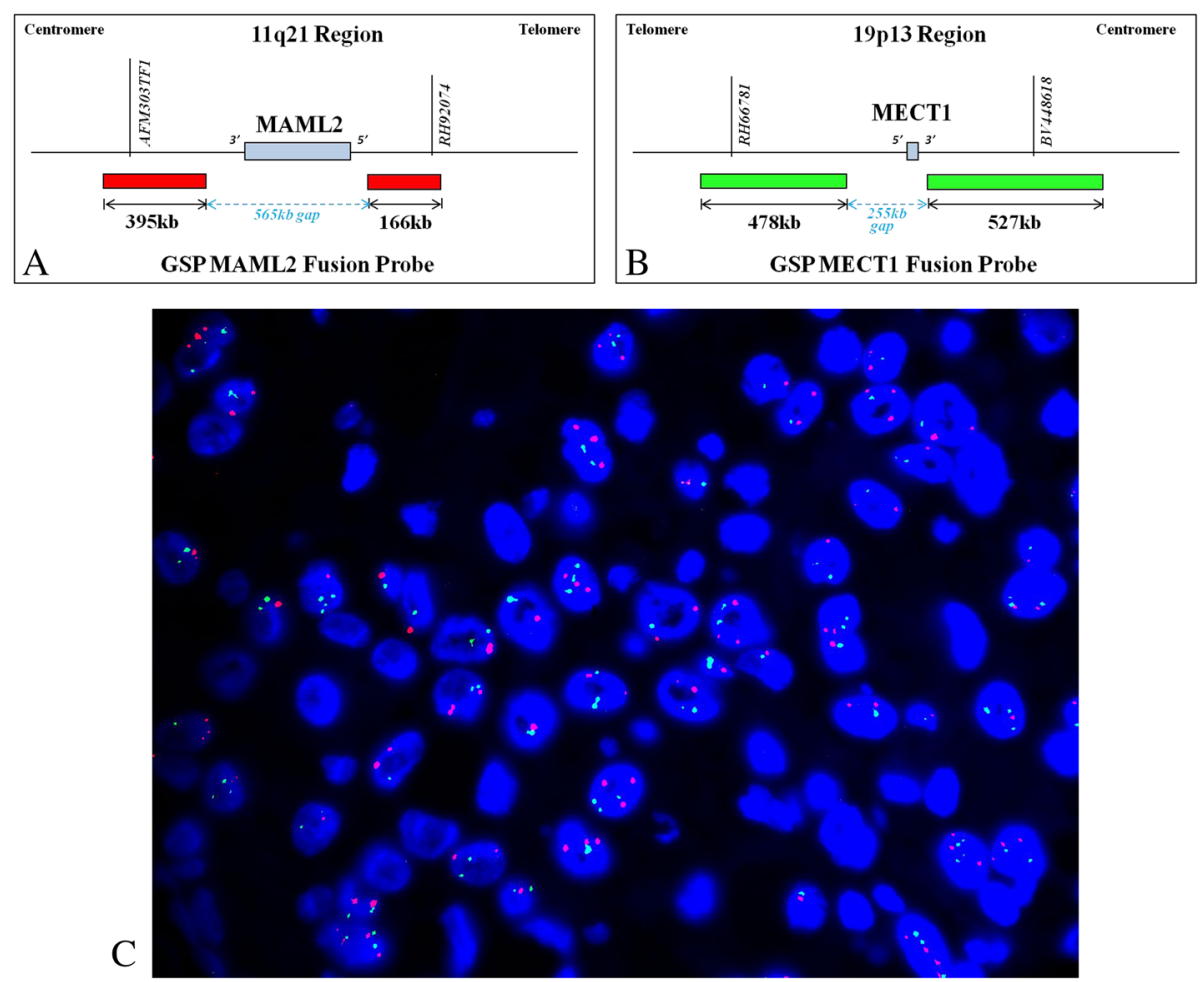

Fig. 4 FISH analysis for the CRTC1/MECT1-MAML2 fusion gene. Probe pattern diagram: GSP CRTC1/MECT1 green fusion probe, GSP MAML2 red fusion probe (top). Non-typical positive signal mode, CRTC1/MECT1-MAML2 fusion gene was negative (bottom)

hepatitis $\mathrm{C}$, long-term alcohol intake history and cirrhosis, like most primary HMEC cases reported in the literature (Table 1). In 2006, Zhu et al. reported an adult male patient, also absent for high risk factors, who was first diagnosed with unusual HCC metastatic to the right proximal ulna and metachronous esophageal squamous cell carcinoma resulting from Fanconi's anemia [24]. Linares et al. reported a 31-year-old female patient with synchronous squamous cell carcinoma of the esophagus and HCC associated with Fanconi's anemia [25]. However, the present case only showed mild anemia, with an absence of the typical phenotype for Fanconi's anemia, which was only present in family members carrying genes for Fanconi's anemia. In fact, increasing evidence has suggested that monoallelic carriers for Fanconi's anemia genes are characterized by an adult-onset predisposition to most solid cancers, especially squamous cell carcinomas from the epithelia of genitourinary tracts and the aerodigestive system [26]. Alter et al. reported that $20-30 \%$ of germline Fanconi's anemia presents with unusual solid malignancies as the first clinic manifestation and shows an absence of the phenotype of congenital Fanconi's anemia [26, 27]. Interestingly, three patients were reported with HMEC, also absent for Fanconi's anemia, combined with synchronous HCC [28], synchronous squamous cell carcinoma in the cranial skin [29] and metachronous gastric malignant carcinoma [30].

The phenotypes of germline Fanconi's anemia mutation-related solid tumors were probably determined in mutation loads or a dose-dependent manner [26]. So far, 22 proteins (FANCA-FANCW/RFWD3) and other Fanconi's anemia network genes have been identified to function in the Fanconi's anemia pathway [31]. These proteins participate in pathways including genome maintenance processes and DNA repair in response to DNA damage, as well as interstrand cross-linking repair, homologous recombination and non-homologous terminal junctions [32]. FANCA variants (c.G1501A:p.G501S and c.A796G:p.T266A) were shown to confer an increased risk for cervical squamous carcinoma [33]. An association with both progression-free and overall survival probabilities was found with the FANCD1/BRCA2 V2466A variant in breast cancer [34]. The Fanconi's anemia protein FAN1 has a small role in interstrand crosslink repair and patients with homozygous mutation in FAN1 did not show Fanconi's anemia features. However, Lachaud et al. showed that FAN1 defects can cause cancers in knock-in mice, and the FAN1 variant in high-risk pancreatic cancers abolishes recruitment by Ub-FANCD2, resulting in genetic instability without 


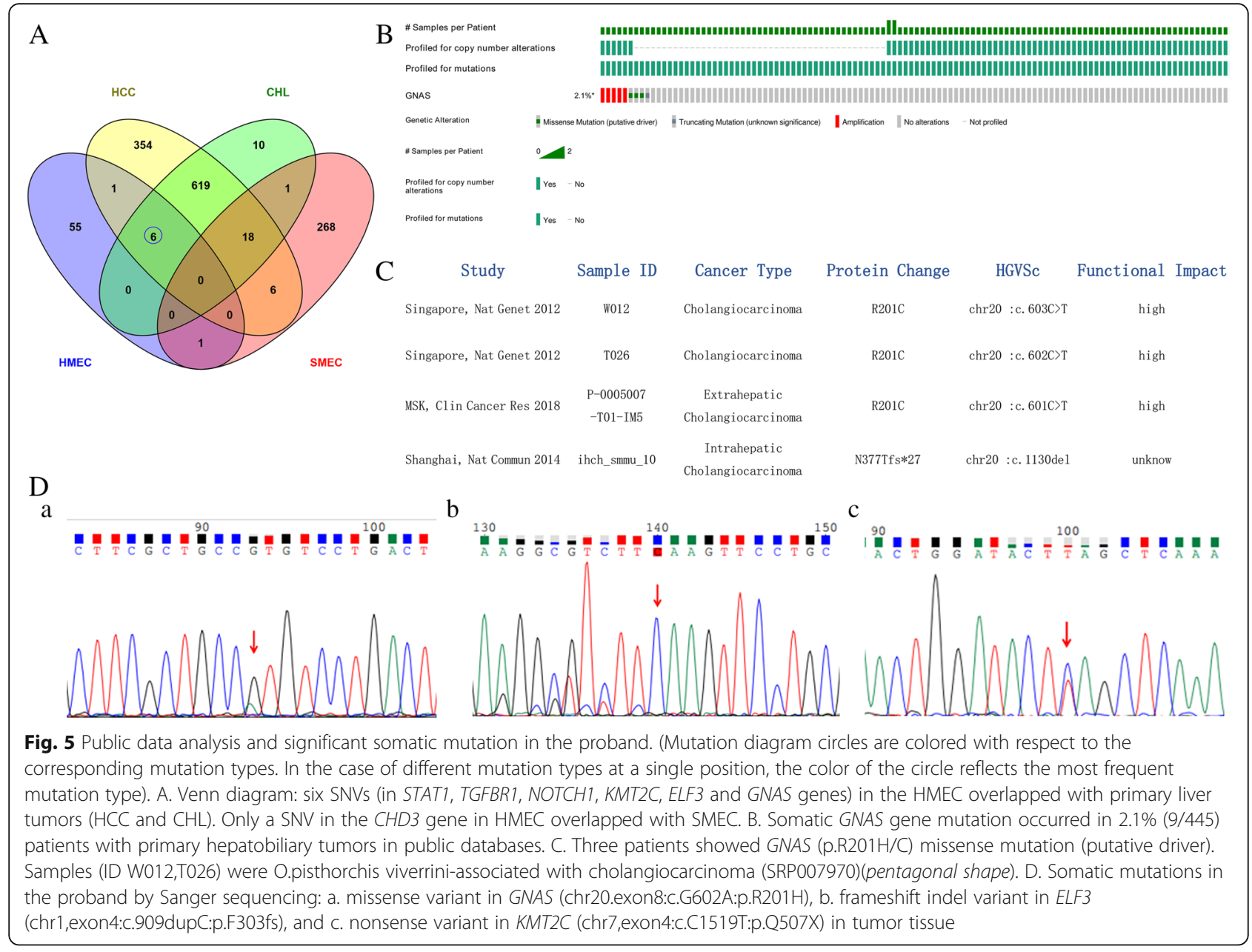

affecting interstrand crosslink repair [35]. Germline FAN1 mutations occur frequently in high-risk pancreatic cancers [36] and hereditary susceptibility to familial colorectal cancers [37]. In the present case, we found that FAN1 mutations were present in the pedigree. Therefore, we propose that germline
Fanconi's anemia gene mutations are likely predisposing factors to the occurrence of HMEC.

Mutations in the GNAS gene typically occur at exon 8, in which Arg201 is converted to either a cysteine (R201C) or a histidine (R201H), leading to activation of the Gos subunit. This Gos constitutively activates the

Table 2 The sanger suquencing of germline variants in proband and family members

\begin{tabular}{|c|c|c|c|c|c|c|c|c|c|}
\hline Gene & Locus & HGVS nomenclature & Alt & Rff & Proband 64y & Sibling 70y & Sibling 61y & Son 39y & Daugther 41y \\
\hline \multirow[t]{2}{*}{ FANCl } & $15 q 26.1$ & exon4:c.C257T:p.A86V & $\mathrm{CT}$ & C & heterozygous & Non & Non & Non & Non \\
\hline & & exon22:c.G2225C:p.C742S & CG & C & heterozygous & Non & Non & Non & Non \\
\hline FAN1 & $15 q 13.2$ & exon2:c.G698A:p.G233E & GA & G & heterozygous & heterozygous & heterozygous & Non & Non \\
\hline FANCJ/BRIP1 & $17 q 23.2$ & exon19:c.T2755C:p.S919P & $\mathrm{TC}$ & $\mathrm{T}$ & heterozygous & homozygous & homozygous & homozygous & homozygous \\
\hline \multirow[t]{3}{*}{ FANCA } & $16 q 24.3$ & exon16:c.G1501A:p.G501S & $\mathrm{CT}$ & C & heterozygous & homozygous & homozygous & homozygous & homozygous \\
\hline & & exon9:c.A796G:p.T266A & $\mathrm{TC}$ & $\mathrm{T}$ & heterozygous & homozygous & homozygous & homozygous & homozygous \\
\hline & & exon26:c.G2426A:p.G809D & $\pi$ & C & homozygous & homozygous & homozygous & homozygous & homozygous \\
\hline \multirow[t]{2}{*}{ FANCW/RFWD3 } & $16 q 23.1$ & exon10:c.A1690G:p.I564V & $\mathrm{CC}$ & $\mathrm{T}$ & homozygous & homozygous & homozygous & homozygous & homozygous \\
\hline & & exon2:c.C269A:p.T90N & $\pi$ & G & homozygous & homozygous & homozygous & homozygous & homozygous \\
\hline FANCD1/BRCA2 & $13 q 13.1$ & exon14:c.T7397C:p.V2466A & GG & A & homozygous & homozygous & homozygous & homozygous & homozygous \\
\hline C17orf70 & $17 q 25.3$ & exon8:c.A2449G:p.T817A & $\mathrm{CC}$ & $\mathrm{T}$ & homozygous & homozygous & homozygous & homozygous & homozygous \\
\hline
\end{tabular}


A

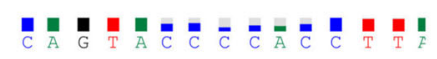

a

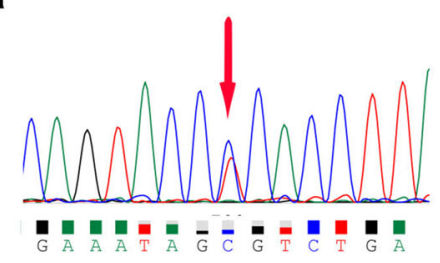

b

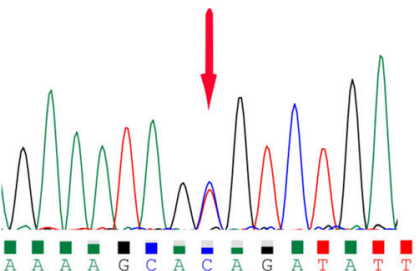

C

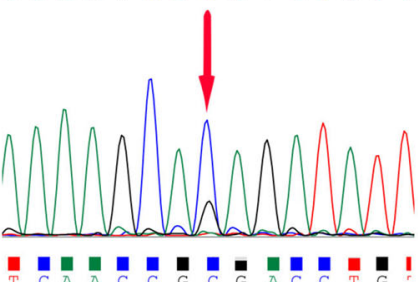

d

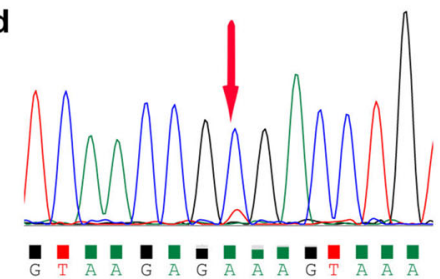

e

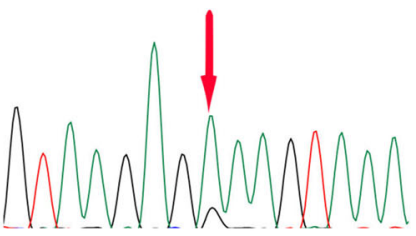

B
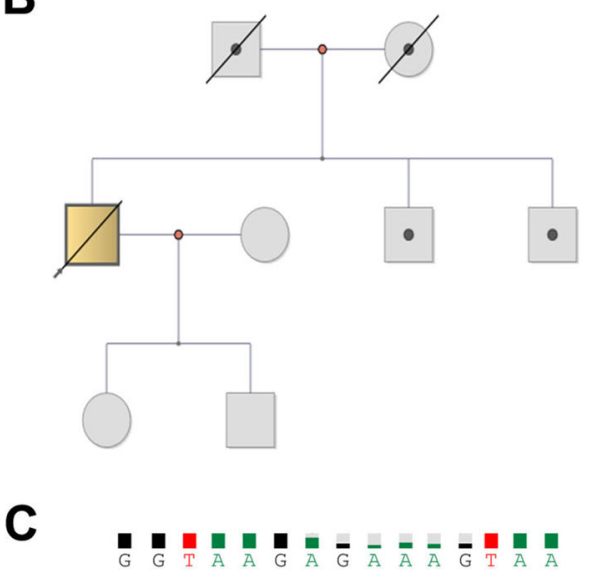

a

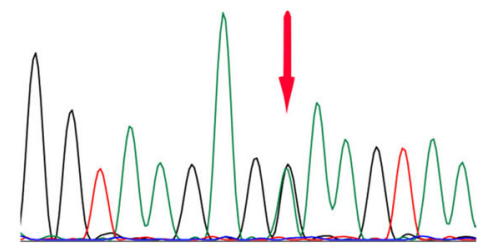

b
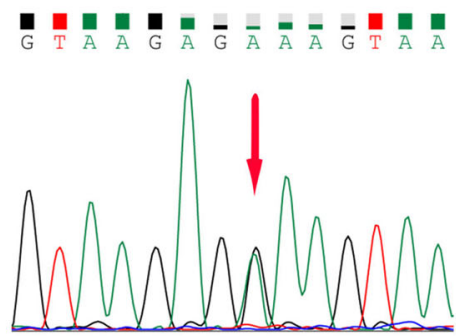

Fig. 6 Germline heterozygous mutations in the proband and pedigree screening. A. a. FANCl (chr15.exon4:c.C257T:p.A86V); b. FANCI (chr15.exon22:c.G2225C:p.C742S); c. FANCJ/BRIP1 (chr17.exon19:c.T2755C:p.S919P), d. FANCA (chr16.exon9:c.A796G:p.T266A); e. FAN1 (chr15.exon2:c.G 698A:p.G233E) (corresponding non-tumor liver tissue). B. Pedigree map: the proband's parents died from cardiovascular and cerebrovascular diseases; there was no obvious Fanconi's anemia disease in the proband's offspring and brothers. C. Siblings A and B, FAN1 (exon2:c.G698A:p.G233E) (blood)

intracellular cyclin adenosine monophosphate signal pathway [38]. The GNAS R201H/C missense mutation have been showed a cross-communication between JAK/ STAT and cyclic-AMP pathways in rare subtypes of liver inflammatory tumorigenesis [39]. Farges et al. also described an adult male patient with inflammatory hepatic adenoma associated with Fanconi's anemia and somatic GNAS mutation who developed malignant transformation of HCC [40]. Consistent with the inflammatory phenotype observed in the present HMEC case, previous studies reported three HMEC patients with inflammation phenotype and inflammatory cell infiltration in the corresponding tumor-free liver tissue [30, 41, 42]. The somatic GNAS $\mathrm{R} 201 \mathrm{H} / \mathrm{C}$ mutation occurs frequently in secreting-mucous tumors like pancreatic intraductal papillary mucinous neoplasms (IPMN) as a bona fide precursor to carcinogenesis [43]. The GNAS R201 mutation was detected in pancreatic IPMN tissue, secretin-stimulated pancreatic juice and peripheral blood [44]. The mucus production and carcinogenesis of the intestinal subtype of intraductal papillary neoplasm of the biliary ducts, a counterpart of pancreatic IPMN, have also been connected with gain-of-function 
mutations of GNAS R201 [45]. The protein-truncating genetic variants in the present case included a frameshift insertion in ELF3 and nonsense mutation in KMT2C, and both genes were also reported in biliary tumors as tumor suppressors [46]. In addition, positive immunohistochemical results for CK7 and CK19 were detected in the present case, which suggests the possibility that HMEC originates from the biliary system [43]. Moreover, GNAS and KMT2C were almost only mutated in Opisthorchis viverrini-induced CHL compared non-O. viverrini-induced CHL [47, 48], which is consistent with the study by Jarley et al. showing that HMEC may be induced in three patients by biliary parasite infection [49]. This may also explain the observation that most HMECs (20/23) were reported in Asian areas with a high incidence of parasites (Table 1).

We also found that the CRTC1-MAML2 fusion gene, which is a specific driver mutation in SMEC, was negative in the present case as examined by FISH. The CRTC1-MAML2 translocation is found in $50-60 \%$ of all SMECs, with the low- and intermediate-grades having a higher percentage of translocations [50]. The present case showed an admixture of malignant epidermoid and mucin-secreting cells in lack of gland formations and keratinization is rarely formed in malignant epidermoid cells, thus favoring a diagnosis of HMEC rather than primary hepatic adenosquamous carcinoma. Immunohistochemical evaluation of the present case also favored HMEC; CEA was focally positive in malignant mucinous cells, while it tends to show diffuse positive staining in primary hepatic adenosquamous carcinoma cells [51].

In conclusion, the molecular characteristics of the current HMEC were more similar to primary liver biliary tumors rather than to SMEC. We present here for the first time the etiology of HMEC associated with germline Fanconi's anemia mutations and somatic GNAS R201 mutation.

\section{Abbreviations}

MEC: Mucoepidermoid carcinoma; HMEC: Hepatic mucoepidermoid carcinoma; SMEC: Salivary mucoepidermoid carcinoma; HCC: Hepatocellular carcinoma; CHL: Cholangiocarcinoma; WES: Whole exome-sequencing; FISH: Fluorescence in situ hybridization; CT: Computer tomography; SNV: Single-nucleotide variant

\section{Supplementary Information}

The online version contains supplementary material available at https://doi. org/10.1186/s13000-021-01086-3.

Additional file 1: Supplementary Figure 1 Somatic variation Circos plot display. Supplementary Figure 2. Public datas (source: Onco KB). Supplementary Table 1. The Primers of somatic and germline mutations. Supplementary Table 2. The germline variants in Fanconi's anemia pathway genes in the proband's corresponding non-tumor tissue by WES.

\section{Acknowledgements}

We thank the generosity of the patient and his family. We would also like to thank Novogene Co., Ltd. and BGI TECH SOLUTIONS (BEIJING LIUHE) CO.,
LIMITED for DNA sequencing services. We also thank Feng Zhang, PhD, from the Institute of Translational Medicine, NanChang University for professional knowledge guidance in sequencing. We also thank Gabrielle White Wolf, PhD, from Liwen Bianji, Edanz Editing China (www.liwenbianji.cn/ac), for editing the English text of a draft of this manuscript.

\section{Authors' contributions}

This study was designed by Ping Hou, Wenjun Liao and Linquan Wu. Manuscript was written by Ping Hou and Xiaoyan Su. Pedigree analysis and clinical phenotype analysis was performed by Ping Hou with further review by Lixiang Li, Xiaoyan Su and Liping Xu. Whole exome sequencing and bioinformatic analysis by Wei Cao, Jiakun Wang, Rongguiyi Zhang, and Zhihao Huang. The author(s) read and approved the final manuscript.

\section{Funding}

This work was supported by CHEN XIAO-PING FOUNDATION FOR THE DEVE LOPMENT OF SCIENCE AND TECHOLOGY; the National Natural Science Foundation of China (N0.81860431 and N0.82060447), the Jiangxi Natural Science Foundation (NO.20181BBG70025).

\section{Availability of data and materials}

We declared that materials described in the manuscript, including all relevant raw data, will be freely available to any scientist wishing to use them for non-commercial purposes, without breaching participant confidentiality.

\section{Declarations}

Ethics approval and consent to participate

This study was approved by the Ethics Committee of the Second Affiliated Hospital of Nanchang University. Informed consent for the surgical procedures was obtained from the patient and his family.

\section{Consent for publication}

Not applicable.

\section{Competing interests}

The authors declare no conflict of interests. The authors declare no competing financial interest.

\section{Author details}

'Department of Hepatobiliary and Pancreatic Surgery, The Second Affiliated Hospital of Nanchang University, No.1, Minde Road, Nanchang, China. ${ }^{2}$ Department of Pathology, The Second Affiliated Hospital of Nanchang University, No.1, Minde Road, Nanchang, China. ${ }^{3}$ Department of General Surgery, The First Affiliated Hospital of Nanchang University, No.17, Yongwaizheng Street, Nanchang, China. ${ }^{4}$ Department of Pathology, The Third Affiliated Hospital of Nanchang University, No.128, Xiangshan Road, Nanchang, China.

Received: 22 October 2020 Accepted: 8 March 2021

Published online: 08 April 2021

\section{References}

1. Nallacheruvu Y, Gaur K, Sakhuja P, Agarwal AK, Srivastava S. Mucoepidermoid carcinoma of the gallbladder: a case-based study of an extremely rare tumor highlighting the role of immunohistochemical profiling. Int J Surg Pathol. 2019;27(4):418-22. https://doi.org/10.1177/1 066896918821436 PubMed PMID: 30587051

2. Tonon G, Modi S, Wu L, Kubo A, Coxon AB, Komiya T, et al. t(11;19)(q21;p13) translocation in mucoepidermoid carcinoma creates a novel fusion product that disrupts a Notch signaling pathway. Nat Genet. 2003;33(2):208-13. https://doi.org/10.1038/ng1083 PubMed PMID: 12539049.

3. Lennerz JK, Perry A, Mills JC, Huettner PC, Pfeifer JD. Mucoepidermoid carcinoma of the cervix: another tumor with the $t(11 ; 19)$-associated CRTC1MAML2 gene fusion. Am J Surg Pathol. 2009;33(6):835-43. https://doi.org/1 0.1097/PAS.0b013e318190cf5b PubMed PMID: 19092631.

4. Achcar RDOD, Nikiforova MN, Dacic S, Nicholson AG, Yousem SA. Mammalian mastermind like 2 11q21 gene rearrangement in bronchopulmonary mucoepidermoid carcinoma. Hum Pathol. 2009:40(6): 854-60. https://doi.org/10.1016/j.humpath.2008.11.007. 
5. Saeki K, Ohishi Y, Matsuda R, Mochidome N, Miyasaka Y, Yamamoto H, et al. "Pancreatic mucoepidermoid carcinoma" is not a pancreatic counterpart of CRTC1/3-MAML2 fusion gene-related mucoepidermoid carcinoma of the salivary gland, and may more appropriately be termed pancreatic adenosquamous carcinoma with mucoepidermoid carcinoma-like features. Am J Surg Pathol. 2018;42(11):1419-28. https://doi.org/10.1097/PAS. 0000000000001135 PubMed PMID: 30138216.

6. Watanabe J, Kai K, Tanikawa K, Hiraki M, Mizukami N, Aishima S, et al. Primary mucoepidermoid carcinoma of the liver with CRTC1-MAML2 fusion: a case report. Diagn Pathol. 2019;14(1):84. https://doi.org/10.1186/s13000-01 9-0863-8 PubMed PMID: 31351495.

7. Moul AE, Bejarano PA, Casillas J, Levi JU, Garcia-Buitrago MT. Mucoepidermoid carcinoma of the Intrapancreatic common bile duct: immunohistochemical profile, prognosis, and review of the literature. Case Rep Pathol. 2013;2013:1-5. https://doi.org/10.1155/2013/192458.

8. Deeg HJ, Socie G, Schoch G, Henry-Amar M, Witherspoon RP, Devergie A, et al. Malignancies after marrow transplantation for aplastic anemia and fanconi anemia: a joint Seattle and Paris analysis of results in 700 patients. Blood. 1996:87(1):386-92. PubMed PMID: 8547667. https://doi.org/10.1182/ blood.V87.1.386.386

9. Li H, Durbin R. Fast and accurate short read alignment with burrowswheeler transform. Bioinformatics. 2009;25(14):1754-60. https://doi.org/10.1 093/bioinformatics/btp324 PubMed PMID: 19451168.

10. Li H, Handsaker B, Wysoker A, Fennell T, Ruan J, Homer N, et al. The sequence alignment/map format and SAMtools. Bioinformatics. 2009;25(16): 2078-9. https://doi.org/10.1093/bioinformatics/btp352 PubMed PMID: 19505943

11. Wang K, Li M, Hakonarson H. ANNOVAR: functional annotation of genetic variants from high-throughput sequencing data. Nucleic Acids Res. 2010; 38(16):e164. https://doi.org/10.1093/nar/gkq603 PubMed PMID: 20601685.

12. Abecasis GR, Auton A, Brooks LD, DePristo MA, Durbin RM, Handsaker RE, et al. An integrated map of genetic variation from 1,092 human genomes. Nature. 2012:491(7422):56-65. https://doi.org/10.1038/nature11632 PubMed PMID: 23128226

13. Sherry ST, Ward MH, Kholodov M, Baker J, Phan L, Smigielski EM, et al. dbSNP: the NCBI database of genetic variation. Nucleic Acids Res. 2001: 29(1):308-11. https://doi.org/10.1093/nar/29.1.308 PubMed PMID: 11125122.

14. Kent WJ, Sugnet CW, Furey TS, Roskin KM, Pringle TH, Zahler AM, et al. The human genome browser at UCSC. Genome Res. 2002;12(6):996-1006. https://doi.org/10.1101/gr.229102 PubMed PMID: 12045153.

15. Cibulskis K, Lawrence MS, Carter SL, Sivachenko A, Jaffe D, Sougnez C, et al. Sensitive detection of somatic point mutations in impure and heterogeneous cancer samples. Nat Biotechnol. 2013;31(3):213-9. https:// doi.org/10.1038/nbt.2514 PubMed PMID: 23396013

16. Saunders CT, Wong WS, Swamy S, Becq J, Murray LJ, Cheetham RK. Strelka: accurate somatic small-variant calling from sequenced tumor-normal sample pairs. Bioinformatics. 2012;28(14):1811-7. https://doi.org/10.1093/ bioinformatics/bts271 PubMed PMID: 22581179.

17. Adzhubei I, Jordan DM, Sunyaev SR. Predicting functional effect of human missense mutations using PolyPhen-2. Curr Protoc Hum Genet. 2013; Chapter 7:t7-20. https://doi.org/10.1002/0471142905.hg0720s76 PubMed PMID: 23315928

18. Ng PC, Henikoff S. SIFT: predicting amino acid changes that affect protein function. Nucleic Acids Res. 2003;31(13):3812-4. https://doi.org/10.1093/nar/ gkg509 PubMed PMID: 12824425.

19. Miosge LA, Field MA, Sontani Y, Cho V, Johnson S, Palkova A, et al. Comparison of predicted and actual consequences of missense mutations. Proc Natl Acad Sci U S A. 2015;112(37):E5189-98. https://doi.org/10.1073/ pnas.1511585112 PubMed PMID: 26269570.

20. Gao J, Aksoy BA, Dogrusoz U, Dresdner G, Gross B, Sumer SO, et al. Integrative analysis of complex cancer genomics and clinical profiles using the cBioPortal. Sci Signal. 2013;6(269):11. https://doi.org/10.1126/scisignal.2 004088 PubMed PMID: 23550210.

21. Cerami E, Gao J, Dogrusoz U, Gross BE, Sumer SO, Aksoy BA, et al. The cBio cancer genomics portal: an open platform for exploring multidimensional cancer genomics data: figure 1. Cancer Discov. 2012;2(5):401-4. https://doi. org/10.1158/2159-8290.CD-12-0095.

22. Kang H, Tan M, Bishop JA, Jones S, Sausen M, Ha PK, et al. Whole-exome sequencing of salivary gland Mucoepidermoid carcinoma. Clin Cancer Res. 2017;23(1):283-8. https://doi.org/10.1158/1078-0432.CCR-16-0720.
23. Zhu AX, D'Andrea AD, Sahani DV, Hasserjian RP. Case 13-2006: a 50-year-old man with a painful bone mass and lesions in the liver. N Engl J Med. 2006; 354(17):1828-37. https://doi.org/10.1056/NEJMcpc069004.

24. Linares M, Pastor E, Gomez A, Grau E. Hepatocellular carcinoma and squamous cell carcinoma in a patient with Fanconi's anemia. Ann Hematol. 1991;63(1):54-5. https://doi.org/10.1007/BF01714963 PubMed PMID: 1652289.

25. Nalepa G, Clapp DW. Fanconi anaemia and cancer: an intricate relationship. Nat Rev Cancer. 2018;18(3):168-85. https://doi.org/10.1038/nrc.2017.116.

26. Alter BP, Greene MH, Velazquez I, Rosenberg PS. Cancer in Fanconi anemia. Blood. 2003;101(5):2072. https://doi.org/10.1182/blood-2002-11-3597 PubMed PMID: 12584146.

27. Kang H, Park YN, Kim SE, Sohn KR, Yoo NC, Park JY, et al. Double primary mucoepidermoid carcinoma and hepatocellular carcinoma of the liver--a case report. Hepatogastroenterology. 2003;50(49):238-41 PubMed PMID: 12630031

28. Nishiyama M, Mizukami Y, Kume M, Ogawa A, Jinno A, Kisaka Y, et al. Mucoepidermoid carcinoma of the intrahepatic bile duct with metastasis to the cranial skin. Nihon Shokakibyo Gakkai Zasshi. 2012;109(11):1953-9 PubMed PMID: 23132041.

29. Hayashi I, Tomoda $H$, Tanimoto $M$, Furusawa $M$, Katsuda $Y$, Shirai $S$, et al. Mucoepidermoid carcinoma arising from a preexisting cyst of the liver. J Surg Oncol. 1987;36(2):122-5. https://doi.org/10.1002/jso.2930360210 PubMed PMID: 3309470

30. Nepal M, Che R, Zhang J, Ma C, Fei P. Fanconi anemia signaling and cancer. Trends Cancer. 2017;3(12):840-56. https://doi.org/10.1016/j.trecan.2017.10.005.

31. Wang AT, Smogorzewska A. SnapShot: Fanconi anemia and associated proteins. Cell. 2015;160(1-2):354-354.e1. https://doi.org/10.1016/j.cell.2 014.12.031.

32. Wang SS, Bratti MC, Rodriguez AC, Herrero R, Burk RD, Porras $C$, et al. Common variants in immune and DNA repair genes and risk for human papillomavirus persistence and progression to cervical cancer. J Infect Dis. 2009;199(1):20-30. https://doi.org/10.1086/595563 PubMed PMID: 19012493.

33. Cecener G, Egeli U, Tunca B, Erturk E, Ak S, Gokgoz S, et al. BRCA1/2 germline mutations and their clinical importance in Turkish breast cancer patients. Cancer Investig. 2014;32(8):375-87. https://doi.org/10.3109/073 57907.2014.919302 PubMed PMID: 24884828.

34. Lachaud C, Moreno A, Marchesi F, Toth R, Blow JJ, Rouse J. Ubiquitinated Fancd2 recruits Fan1 to stalled replication forks to prevent genome instability. Science. 2016;351(6275):846-9. https://doi.org/10.1126/science.aa d5634.

35. Smith AL, Alirezaie N, Connor A, Chan-Seng-Yue M, Grant R, Selander I, et al. Candidate DNA repair susceptibility genes identified by exome sequencing in high-risk pancreatic cancer. Cancer Lett. 2016;370(2):302-12. https://doi. org/10.1016/j.canlet.2015.10.030.

36. Segui N, Mina LB, Lazaro C, Sanz-Pamplona R, Pons T, Navarro M, et al. Germline mutations in FAN1 cause hereditary colorectal cancer by impairing DNA repair. Gastroenterology. 2015;149(3):563-6. https://doi.org/1 0.1053/j.gastro.2015.05.056 PubMed PMID: 26052075.

37. O'Hayre M, Vázquez-Prado J, Kufareva I, Stawiski EW, Handel TM, Seshagiri S, et al. The emerging mutational landscape of $\mathrm{G}$ proteins and G-proteincoupled receptors in cancer. Nat Rev Cancer. 2013;13(6):412-24. https://doi. org/10.1038/nrc3521.

38. Nault JC, Fabre M, Couchy G, Pilati C, Jeannot E, Tran Van Nhieu J, et al. GNAS-activating mutations define a rare subgroup of inflammatory liver tumors characterized by STAT3 activation. J Hepatol. 2012;56(1):184-91. https://doi.org/10.1016/j.jhep.2011.07.018.

39. Di Palma S, Andreola S, Audisio RA, Doci R, Lombardi L. Primary mucoepidermoid carcinoma of the liver. A case report. Tumori. 1992;78(1): 65-8. PubMed PMID: 1609465. https://doi.org/10.1177/030089169207800117.

40. Katsuda S, Nakanishi I, Kajikawa K, Takabatake S. Mucoepidermoid carcinoma of the liver. Acta Pathol Jpn. 1984;34(1):153-7. https://doi.org/10.1111/j.144 0-1827.1984.tb02194.x PubMed PMID: 6730963.

41. Patra KC, Kato Y, Mizukami Y, Widholz S, Boukhali M, Revenco I, et al. Mutant GNAS drives pancreatic tumourigenesis by inducing PKA-mediated SIK suppression and reprogramming lipid metabolism. Nat Cell Biol. 2018;20(7): 811-22. https://doi.org/10.1038/s41556-018-0122-3.

42. Berger AW, Schwerdel D, Costa IG, Hackert T, Strobel O, Lam S, et al. Detection of hot-spot mutations in circulating cell-free DNA from patients with intraductal papillary mucinous neoplasms of the pancreas. 
Gastroenterology. 2016;151(2):267-70. https://doi.org/10.1053/j.gastro.2016 04.034 .

43. Nakamura H, Arai Y, Totoki Y, Shirota T, Elzawahry A, Kato M, et al. Genomic spectra of biliary tract cancer. Nat Genet. 2015;47(9):1003-10. https://doi. org/10.1038/ng.3375.

44. Chan-on W, Nairismägi M, Ong CK, Lim WK, Dima S, Pairojkul C, et al. Exome sequencing identifies distinct mutational patterns in liver fluke-related and non-infection-related bile duct cancers. Nat Genet. 2013;45(12):1474-8. https://doi.org/10.1038/ng.2806.

45. Ong CK, Subimerb C, Pairojkul C, Wongkham S, Cutcutache I, Yu W, et al. Exome sequencing of liver fluke-associated cholangiocarcinoma. Nat Genet. 2012;44(6):690-3. https://doi.org/10.1038/ng.2273.

46. Koo J, Ho J, Wong J, Ong GB. Mucoepidermoid carcinoma of the bile duct. Ann Surg. 1982;196(2):140-8. https://doi.org/10.1097/00000658-19820800000005 PubMed PMID: 7092364

47. Jee K, Persson M, Heikinheimo K, Passador-Santos F, Aro K, Knuutila S, et al. Genomic profiles and CRTC1-MAML2 fusion distinguish different subtypes of mucoepidermoid carcinoma. Mod Pathol. 2013;26(2):213-22. https://doi. org/10.1038/modpathol.2012.154

48. Yan L, Xie F, Yang C, Yu L, Zheng T, Fu J, et al. The comparison of surgical patients with primary hepatic squamous cell carcinoma or adenosquamous carcinoma and surgical patients with hepatocellular carcinoma. World J Surg Oncol. 2015;13(1):90. https://doi.org/10.1186/s12957-015-0464-2.

49. Boeva V, Popova T, Bleakley K, Chiche P, Cappo J, Schleiermacher G, et al. Control-FREEC: a tool for assessing copy number and allelic content using next-generation sequencing data. Bioinformatics. 2012;28(3):423-5. https:// doi.org/10.1093/bioinformatics/btr670 PubMed PMID: 22155870.

50. Farges O, Ferreira N, Dokmak S, Belghiti J, Bedossa P, Paradis V. Changing trends in malignant transformation of hepatocellular adenoma. Gut. 2010; 60(1):85-9. https://doi.org/10.1136/gut.2010.222109.

51. Yang CY, Huang WJ, Tsai JH, Cheng A, Chen CC, Hsu HP, et al. Targeted next-generation sequencing identifies distinct clinicopathologic and molecular entities of intraductal papillary neoplasms of the bile duct. Mod Pathol. 2019;32(11):1637-45. https://doi.org/10.1038/s41379-019-0306-9 PubMed PMID: 31231124.

\section{Publisher's Note}

Springer Nature remains neutral with regard to jurisdictional claims in published maps and institutional affiliations.

Ready to submit your research? Choose BMC and benefit from:

- fast, convenient online submission

- thorough peer review by experienced researchers in your field

- rapid publication on acceptance

- support for research data, including large and complex data types

- gold Open Access which fosters wider collaboration and increased citations

- maximum visibility for your research: over $100 \mathrm{M}$ website views per year

At $\mathrm{BMC}$, research is always in progress.

Learn more biomedcentral.com/submissions 